\title{
Symbolic Meanings in the Ghanaian Arts: A Step Towards Developing Cultural Literacy
}

\author{
Robert Ayiku
}

\author{
Statement of Purpose
}

This study proposes to document some aspects of the indigenous cultural arts of Ghana. Its goals are to: 1) identify and interpret some key symbolic expressions as found in particular examples of visual, performing, and verbal art forms, and 2) state the significance of these expressions and art forms in the everyday life and living of the people of Ghana. The documentation of these symbolic expressions will be done in a way to make them directly applicable as educational material in Ghanaian schools. This application to teaching will involve following the model of Discipline-Based Arts Education (D.B.A.E.).

\section{Statement of the Problem and Discussion}

Since the second half of the nineteenth century, the cultural arts of Ghana have suffered a considerable setback due to foreign influences. The major foreign factors influencing Ghanaian artistic expression include religion such as Christianity and Islam, as well as formal (Westem) schooling.

Christian missionaries to Ghana have rejected many indigenous Ghanaian customs, beliets, and values because these do not contorm to the Western culture which they have sought to impose on the people of Ghana. These missionaries have viewed the cultural life of the people of Ghana as primitive, idolatrous, paganistic, and childish. As such, they have described the whole cultural system as "fetishistic," implying it is unreal, superstitious, and magical.

Like Christianity, Islam has also attacked and denounced the Ghanaian culture. It has taught "monotheism," an ideology that emphasizes the existence of only one God, called Allah, and therefore condemned the Ghanaian indigenous religious practices as the worship of many gods. Islam does not allow figurative representation of deities in any visual art forms, a practice that is central to indigenous religious practices in Ghana.

The consequences of these forces of acculturation are diversified, but the most prominent is that most Ghanaian religious converts have become confused, thereby losing confidence in their indigenous cultural arts and developing ambivalent or lukewarm attitudes towards them. Due to Christian teaching, many Ghanaians who have received Western education have also shitted to Western types of life styles, thus influencing the lifestyles of many other Ghanaians, especially urban dwellers and the youth. Among the Westerninfluenced elite of Ghana, attitudes towards the arts are varied, but the most prominent is the tendency to look down on indigenous arts and artists. The arts are regarded as intellectually undemanding as compared to disciplines like 
mathernatics, engineering, and science, which are perceived as difficult because they require skills of abstraction, conceptualization, and computation. In light of these attitudes, most parents of this elite group encourage and persuade their children to study science or something else other than art. These attitudes can be attributed in large part to the fact that the system of schooling was such that it did not help much of the Ghanaian public to understand the role of the arts in education and the society-at-large.

In an attempt to rectify this situation, the Ministry of Education and Culture of Ghana has instituted a "Curriculum Enrichment Programme" as part of the educational system of Ghana. In this programme, the Ghanaian cultural arts are incorporated as an interdisciplinary study at the basic level of education. By basic level of education is meant, from Kindergarten to the Junior Secondary School level, with ages ranging from approximately five to sixteen years old. The primary aim of this programme, which began in $1984 / 85$, has been to create an opportunity for the indigenous Ghanaian arts to be brought to all students by integrating them with all subjects in the school programme. This has resulted in the arts being treated as a supporting content of the general education programme.

Although they are included in the curriculum, the arts are not treated as full-fledged disciplines. While other subjects are taught with a concern for content, continuity, and consistency to enable learners to understand and achieve the rudimentary principles and basic literacy, and included within the schedule of daily instruction, learning in the arts tends to be treated as an ancillary activity - a recreational diversion from vigorous academic work. This is because there have been no specifically accepted guidelines regarding how instruction in the arts is to be carried out so as to result in a meaningtul and purposeful learning for the students. Thus the potential is lost for the arts in assisting to "expand the students' capacity to create, to empathize, and to gain access to their own feelings" as part of the leaming process (Bell, 1987, p.43). As such, the value of the ants in everyday life fails to manilest itself in the learner. This disparity between the goals and priorities of general education and arts education, as well as the imbalance between instruction in the arts and other subject areas, have resulted in denigrating the image of the arts, thereby relegating them to a very low ebb among educators, students, and the general Ghanaian public

The foregoing problems suggest a need for a careful reexamination of the goals and priorities for teaching and learning in the arts in Ghana. First, there is the need for documented material that would validate the indigenous Ghanaian arts so that they can serve to build the cultural identity and self-identity of Ghanaians. Second, there is need to reexamine and find ways to improve the place of arts education as it is currently practised in the Ghanaian school curriculum, to raise the status arts education from an ancillary to a full-fledged discipline, comprised of the study of history, criticism, and aesthetics of the Ghanaian arts, as well as their - production. It is, therefore, to this end that this research is proposed

Marilyn Zurmuehlen's Working Papers In Art Education 1996-1997 


\section{Specific Objectives}

The first objective of this study is to identify and document some key symbolic expressions as found in particular indigenous Ghanaian cultural behaviours, actions, and artifacts. Aspects of the Ghanaian cultural arts to be used for the study will include visual, performing, and verbal art forms. The documentation will include meanings associated with the identified symbolic expressions, their significance or social relevance (that is, the circumstances or events in which they function in Ghanaian cultural activities), historical information, and relationships to aesthetic values of the culture, for example, notions of beauty

The second objective is to propose some strategies for carrying out instruction in arts education at the basic and secondary levels of education in Ghana, using these documents. The proposed strategies will use the DisciplineBased Arts Education (D.B.A.E.) model, which integrates studio practice with the study of the historical, aesthetic, and critical domains of the arts. The goal of this instructional approach is to provide the learners with a more comprehensive approach to acquiring knowledge, skills, and understandings for appreciating works art, including their own indigenous cultural arts. It is also a means to help them to acquire a sense of cultural identity and self-identity.

\section{Conceptual Framework}

This study is based upon the assumption that the indigenous Ghanaian cultural arts are a bona fide part of the cultural heritage of Ghana. Having been linked and bound to the social structure of the Ghanaian society, these indigenous arts are "the most visible and revealing aspects" of the Ghanaian culture through which the ideals, beliefs, and values of the people of Ghana are expressed, communicated, and transmitted from one generation to another (Blocker, 1988, p.13).

That the Ghanaian cultural arts are agents of communication is an indication that they are essentially constituted of "ideational expressions". According to Chalmers (1978), ideational expressions are symbol systems that convey ideas and express emotions, quality, and feelings. The also show rank, status, and role, as well as influence decisions of a group of people (p. 6). This understanding indicates that the indigenous Ghanaian cultural arts are essentially made up of symbol systems or structures that embody the cultural knowledge, including the aesthetic precepts of the people of Ghana. Being reservoirs of the Ghanaian cultural knowledge, these symbol systems are used by Ghanaians to portray and interpret various aspects of their cultural behaviours, practices, and lived experiences. Using this conceptual framework, the study will identify several examples of the various arts, and interpret the meanings of the symbol systems used, and describe their significance.

\section{Significance of the Study}

This researcher envisions the findings of this study being used as educational material for general knowledge in the Ghanaian arts, to enable the

Marilyn Zurmuehlen's Working Papers In Art Education 1996-1997 
people of Ghana, especially the youth, to understand and acquire the relevant literacy for effective participation in, and appreciation of their culture. This vision is based on the following view of the arts and their place in the education of Ghanaians. By leaming about the arts in their own cultural context, students will understand how the arts are constituted: the arts present symbolic meanings that derive from cultural contexts informing both their production and perception. Students will learn that both the contents and contexts of the arts are socially constituted, thereby making explicit the relationship between the arts and their Ghanaian socio-cultural identity. Through this means, students will understand that our ability to visualize, respond, and express ourselves symbolically is a result of experience gained through culturally embedded values, attitudes, and behaviours. It is basically the notion of symbolic meanings as expressed through the arts that grounds the cultural literacy approach to arts education which this study seeks to portray. The contention here is that a cultural literacy approach to arts education involves the study of art forms and processes, from hands-on production through historical, aesthetic, and critical perspectives, as well as an understanding of the socio-cultural constructs which influence how the arts are practised and valued.

As a benefit of a candid and positive exposure to the cultural arts, the student may discover certain personal meanings, reasoning, inquiry, knowing, and intrinsically creative values 'that are a part of the process and product of the arts" (Kautman, 1966 p. 258). Such life enhancing competencies, according to Kaufman, raises the consciousness of the individual, leading to self actualization. Kautman views a self-actualizing person as "one who brings his [or her] own personality in his [or her] interactions or transactions with other people and the general environment to a creative truition" (p.258). Thus an important characteristic of any self-actualizing individual is a measure of personal fulfillment in a variety of ways. Such ways may include enhanced tendencies or capabilities for cultural participation, as well as analyzing and synthesizing information and other phenomena for personal meaning-making in learning situations. This, in turn, will lead to authentication of knowledge and self-expression, which the individual can apply to solve some of the problems and tensions of human existence.

\section{Rationale}

While the cultural policy of Ghana seeks to offer her people opportunities to revive and preserve their indigenous culture, not much has been done in terms of documenting the Ghanaian cultural elements for both cultural record and educational purposes. A high rate of illiteracy among the expert practitioners of indigenous Ghanaian cultural arts has hindered the recording of the cultural heritage; the major means of communicating and transmitting cultural ideals from one generation to another has been by oral tradition. Today, a new urge for cultural identity among Ghanaians has resulted in an increased demand on the few cultural resource persons, most of whom are old and are losing their memory -- the main vehicle for the oral tradition. This therefore indicates the need for the documentation of various aspects of the Ghanaian cultural arts for record purposes, and for use as reading material for educating the younger generations

Marilyn Zurmuehlen's Working Papers In Art Education 1996-1997 
about their culture. The onus is on arts educators, art historians, ethnographers and specialists in other related fields to research into, and document various aspects of the Ghanaian culture for use as educational and reference material. This project will make a contribution towards meeting these needs.

The discipline-based art education (D.B.A.E.) approach to instruction and learning in the arts will be used as a means of bringing about a shift from the usual dependence on studio activities as the only means of education in the arts. a practice that is common in most Ghanaian primary and secondary school classrooms. Often, the Western arts have been taught in Ghanaian schools as studio- or production- oriented. This approach emphasizes students working with various art materials and techniques for the purposes of self-expression and creativity. Too often, there is little concern for developing students' knowledge and skills in other dimensions of the arts, such as the aesthetic, critical, and historical, thereby rendering their appreciation of the world of art relatively limited To rectify this unsatisfactory state of arts education, the discipline-based arts education model is being proposed. By including the aesthetic, critical, and historical dimensions in the proposed learning strategies, other modes of knowing besides studio practice will be included to foster understanding, interpretation, and appreciation of the arts as agents for the transmission of symbolic meanings of the social and cultural contexts from which they derive. Ideally, to borrow Greer's (1984, p. 213) phrase, the "educational end-in-view" of the D.B.A.E. approach to instruction and learning in the arts is to produce educated adults (beings) who are knowledgeable in the arts and their production and responsive to the aesthetic properties of works of art.

\section{Operational Definitions}

Culture may be defined as "those patterns of meaning that any group of people, or society uses to evaluate itself". Thus it can be said to be "a constitutive dimension of all human action" (Bellah et al., 1986, p.333). Such cultural pattems embrace "all the peculiar valuations, institutions, and systems of orientation in guidance (such as folkways, mores, laws, habits, customs. etiquette, fashions) which... characterize ñ if not constitute ñ any social group at a given moment in its history" (Schuts, 1971, p.92). More simply stated, culture is the sum total of the ways of living built up by a group of peoples in any particular society and transmitted from one generation to another.

A symbol in this study is defined as a material expression or form conventionally standing for an idea, a belief, process or act.

Cultural literacy, is defined as the acquisition of cultural knowledge for purposes of social adaptation. It entails the act or process of understanding and the ability to verbalize the assumptions and values that constitute one's own cultural .leritage (Hamblen and Gales, 1991, p. 15). Thus, the theme of the research, "Symbolic Meanings in the Ghanaian Arts: A Step towards Developing Cultural Literacy," entails decoding or encoding the assumptions and values that make up bodies of knowledge and modes of action in indigenous Ghanaian artistic expressions.

Marilyn Zurmuehlen's Working Papers in Art Education 1996-1997 


\section{Methodology}

\section{Methodological Framework}

The methodological framework to be used in this study derives from the study of culture as a system of meanings a people attribute to phenomena. Being a phenomenon of shared meanings, culture is learned and detined in the contexi of interaction between people. Based on this premise, the researcher will use qualitative and ethnographic approaches, adopting a phenomenological perspective for the documentation portion of the study. A phenomenological inquiry involves a study of essences, that is, the essential or very nature of phenomena as are meaningfully experienced. Thus, to question the essence of an aspect of human experience is to make a phenomenological inquiry into the essential nature of a certain way of being in the world. Basically, phenomenological research attempts to describe and interpret experiential meanings as we live them in our everyday existence, our "lifeworld" (van Manen, 1992, p.11). Underlying this idea is the contention that since artists often give shape to their thoughts and lived experiences through their artistic activities; products of art are, in a sense, lived experiences transformed into transcended configurations ( $p .74)$. The phenomenological orientation of this research project lies in its central concern to systematically attempt to describe and interpret the meaning structures of symbolic forms and expressions found in several examples of the Ghanaian cultural arts.

\section{Data Collecting Activities}

Data collection will involve two processes which would take place concurrently because each process supplements and complements the other. One data collection process will include the researcher taking part directly in selected Ghanaian cultural activities such as child-outdooring and naming ceremonies, puberty rites, funerals, and festivals, as well as in recreational activities such as drumming and dancing, drama, and storytelling. The other means of data collection will be by in depth interviews with key respondents in the cultural arts.

The interviews will take the form of phenomenologicat conversation -a dialogic way of questioning and answering. The conversation will have a "hermeneutic thrust" (van Manen, 1992, p.98). This means a mutual or collaborative conversational relationship between the researcher and respondent that will keep both of them constantly thinking, and making sense of the symbolic systems in the Ghanaian cultural arts and interpreting the meanings embedded in them. Questions for the interviews will be semi-structured and open-ended, but within a framework based on obtaining information about particular symbols, their meanings in relation to aesthetic values, historical, and socio-cultural contexts. The specific types of information to be gathered are: 1) what the symbol is: 2) what the symbol means; and 3) how the symbol is used.

\section{Selection of Respondents}

The informants and interview respondents of this study will include artists-in-residence at Centres for National Culture, and cultural experts (mostly,

Marilyn Zurmuehlen's Working Papers In Art Education 1996-1997 
senior citizens) in the courts of selected traditional chiets with paramountcy status in Ghana. The phrase, "chiets with paramountcy", otherwise known as "Paramount Chiets", designates Ghanaian traditional chiefs whose status and placement give them power to rule over large areas of land (or districts) made up of towns and villages with chiefs of lower ranks, including sub-chiefs. Often, such areas of land are comprised of people of the same tribe, language, or traditional behaviours and, are therefore, known as traditional areas.

Key respondents among artists-in-residenœ at Centres for National Culture will be selected according to each person's field of specialization or knowledge in one or more of the three domains of art, namely, the visual, performing, and verbal art forms. On the other hand, most indigenous cultural experts among elders of traditional chiefs' courts of Ghana do not specialize in knowledge about specific cultural arts. While it is not uncommon to find one cultural expert in a traditional chief's court with a sound knowledge in all three chosen fields of art, often, these experts work in groups. The number of persons in each of such groups vary from one court to another, but may range from two to five. Thus, an interview with such a group may take on the form of a seminar (group discussion), with all the participants speaking freely to the subject matter. Through this means, information would be gained about symbolic forms and expressions in all three chosen domains of Ghanaian art. Key respondents in the courts of chiefs will be reached through contact with such teams. The in-depth interviews will be supplemented with informal interviews with other persons the researcher would encounter spontaneously during cultural activities in which he would participate.

\section{Gaining Access to Respondents}

Access to potential respondents would be sought by the researcher in two ways. Letters of application will be sent to the Heads of Centres for National Culture prior to visiting them. This is to enable the researcher to obtain permission for access to the institutions, for observation and to hold interviews with the cultural experts and artists-in-residence. The letters will explain concisely:

- what the research is about;

- the aspects of Ghanaian symbols and cultural arts that would be covered:

- the form of information the research seeks to gain about those cultural arts:

- and the intended or expected end purpose of the research findings.

The application will also seek permission for the researcher to take pictures and to videotape some cultural activities and artifacts relevant to the research.

Access to the courts of chiefs will be gained by the researcher consulting personally with the chiets' elders who act as gate-keepers to the courts. As custom demands in Ghana, drinks -- usually, a bottle each of Schnapps and "Akpeteshie" (a local gin) -- may be presented to the elders where necessary

Marilyn Zurmuehlen's Working Papers In Art Education 1996-1997 
(or as tradition demands in each traditional area). The gate-keepers will then introduce the researcher to the cultural experts of the court for appointments to be made for observations and interview meetings.

\section{Data Analysis}

Analysis of the data will commence in the field as an ongoing part of the data collection. The respondents would depend to a large extent on their memory and personal experiences. Therefore the interview responses will likely be long and open-ended. As such, the resulting amount of data could be enormous, rendering the work of transcribing cumbersome, and rather too complex for convenient handling. To avoid these problems, each interview tape will be selectively transcribed immediately after the interview session, and the contents organized by coding categories. This will involve translating units of the data, that is, the interview responses and other forms of respondent information (gestures and other body language), into categories identified for the interview topics. While reading through the information obtained, the researcher will be assigning the content to predetermined coding categories by means of charting. The chart will be made up of three columns. In the first column will be recorded the names of symbols identified during the interview. The second column will embrace the interpretations of those symbols, and the third column, their functions or social relevance (i.e. the circumstances or events in which they are used). The table that follows illustrates how the interview responses will be categorized.

\begin{tabular}{|l|l|l|}
\hline $\begin{array}{l}\text { WHAT IS THE NAME } \\
\text { OFTHE SYMBOLOR } \\
\text { ARTIFACT? }\end{array}$ & $\begin{array}{l}\text { INTERPREIATION: } \\
\text { WHAT DOESIT } \\
\text { MEAN? }\end{array}$ & $\begin{array}{l}\text { FUNCTIONS: } \\
\text { HOWISIT USED? } \\
\text { (SOCIAL RELEVANCE } \\
\text { ORSIGNIFICANCE) }\end{array}$ \\
\hline $1 \ldots$ & $1 \ldots$ & $1 \ldots$ \\
$2 \ldots$ & $2 \ldots$ & $2 \ldots$ \\
$3 \ldots$ & $3 \ldots$ & $3 \ldots$ \\
\hline
\end{tabular}

Content of the interviews will be verified by reviewing the content of interview responses with the respondents. These reviews will serve as occasions for both researcher and respondents to reflect on the ongoing record of the interview transcript. Since the respondents will depend largely on their memory and personal experiences in responding to the interview questions, the salient points raised by individual respondents will be compared with each other. This is to clarify and corroborate similarities, commonalities, and differences in the information obtained. The findings will, in turn, be integrated with the findings as a result of the researcher's actual partaking in Ghanaian cultural activities and casual interactions with the local participants. This is to clarify the similarities 
and/or commonalities between the verbal information and what pertains in actual practice. In this way, the researcher will ascertain the validity and/or integrity of the data obtained. The data will then be collated and presented in light of the research objectives, using a phenomenological description. The object of phenomenological description, according to van Manen, is to develop a narrative that lays bare the meanings of our daily existence. Specific examples of particular artistic expressions will be cited with reference to specific tribes or traditional areas. The described cultural activities will be illustrated by means of drawings. photographs, or video recordings.

\section{Expected Results}

It is envisaged that the outcome of this study will be a body of documented material that would validate information about the indigenous Ghanaian arts so that they can serve as educational material for Ghanaian schools, as well as for record purposes. Additionally, an approach to teaching and learning in the Ghanaian arts, based on the discipline-based arts education (D.B.A.E.) model, will be proposed. The documented body of literature on the Ghanaian cultural arts together with the suggested approaches to arts education will result in an arts programme that is appropnate for Ghanaian schools. It is intended to offer learners the opportunity to study the arts they have been living with as part of their lifestyle. In this way, the learners' artistic skills and practices, imagination, knowledge, and judgment would be grounded in their own indigenous cultural assumptions. This would render learning meaningtul, thereby serving to build the cultural identity and selt-identity of the learners.

On the whole, this research project would offer exemplary strategies that can be used as a model for studying other aspects of the Ghanaian culture, and also, other studies towards improving arts education in Ghana.

\section{References}

Bellah, R.N. et al., (1986). Habits of the heart. Berkeley, California: University of California Press.

Blocker, Robert L. (July/August 1988). The arts : Reflections of society. Design for Arts in Education, 89 (6), 13-17.

Bogdan, Robert C. and Biklen, Sari Knopp (1991). Qualitative research for education: An introduction to theory and methods. Toronto: Allyn and Bacon, Inc.

Chalmers, G.F. (1981). Art education as ethnography. Studies in Art Education, 22: 6-14.

Cultural Policy in Ghana (1975). A study prepared by the Cultural Division of the Ministry of Education and Culture, Accra, Ghana. The Unesco Press, Pans. 
Dobbs, S.M. (1992). The D.B.A.E. handbook: An overview of Discipline-Based Art Education. The Getty Centre for Education in the Arts, Santa Monica: California

Greer, W. Dwaine (Summer 1984). Discipline-Based Art Education: Approaching art as a subject of study. Studies in Art Education, 25: 212-218.

Hamblen, Karen A. \& Galanes, Camile (Nov. 1991). Instructional optıons for aesthetics: Exploring the possibilities. Art Education, 44 (6). 12-24.

Johnson, Nancy R. (1989). DBAE and cultural literacy ant education. Journal of Social Theory in Art Education, 9, 45-48.

Kaufman, Irving(1966). Art and education in contemporary culture. New York: Macmillan.

Schutz, Alfred (1971). Studies in social theory: Collected papers. (Broderson, Arvid. Ed.), Martinus, Nijhoff, The Hague.

Spradley, James P. (1980). Participatory observation. Toronto: Holt. Rinehart and Winton Inc.

van Manen, Max (1992). Researching lived experience: Human science for an action sensitive pedagogy. Ann Arbor, Michigan: The Althouse Press. 